\title{
Synergistic effect of Mucuna pruriens and Withania somnifera in a paraquat induced Parkinsonian mouse model $^{*}$
}

\author{
Jay Prakash", Satyndra Kumar Yadav ${ }^{1}$, Shikha Chouhan ${ }^{1}$, Satya Prakash ${ }^{2}$, Surya Pratap Singh ${ }^{1 \#}$ \\ ${ }^{1}$ Department of Biochemistry, Faculty of Science, Banaras Hindu University, Varanasi, India \\ ${ }^{2}$ Biomedical Technology and Cell Therapy Research Laboratory, Department of Biomedical Engineering, Faculty of Medicine, \\ McGill University, Montreal, Canada \\ Email: jaiprakash biotech@yahoo.co.in, satyndra_yadav@yahoo.co.in, shikhachouhan16@gmail.com, satya.prakash@mcgill.ca, \\ "suryasinghbhu16@gmail.com, ${ }^{\#}$ ssingh35@,bhu.ac.in
}

Received 2 August 2013; revised 2 September 2013; accepted 21 September 2013

Copyright (C) 2013 Jay Prakash et al. This is an open access article distributed under the Creative Commons Attribution License, which permits unrestricted use, distribution, and reproduction in any medium, provided the original work is properly cited.

\begin{abstract}
Parkinson's disease (PD) is a neurodegenerative disorder characterized by the development of rigidity, resting tremors and postural instability. Recently, the focus of PD's treatment has shifted towards herbal medicines. Mucuna pruriens (Mp) and Withania somnifera (Ws) are traditional herbal medicines known to have neuro-protective effects due to the L-DOPA present in Mp seed powder and withanoloides present in Ws root extract. Here, the synergistic effect of Mp and $\mathrm{Ws}$ in Parkinsonian mice induced by chronic exposure to paraquat was evaluated. Co-treatment with Mp and Ws for 9 weeks, significantly decreased the elevated nitrite levels and lipid peroxidation found in Parkinsonian mice. In behavioural tests, Mp and Ws treated mice showed a significant decrease in the time taken to cross a narrow beam, an increase in the time of stay on drum in rotarod test and an improvement in the hanging time. Furthermore, it was found that the use of Mp and Ws considerably improved the tyrosine hydroxylase expression in the substantianigra region of the brain. The results suggest that Mp and Ws may provide a platform for future drug discoveries and novel treatment strategies for PD.
\end{abstract}

Keywords: Withinia somnifera; Mucuna pruriens; Oxidative Stress; Tyrosine Hydroxylase; Parkinson's Disease; Substantia nigra; Motor Dysfunctions

\footnotetext{
"The study was supported financially by Department of Science and Technology (100/(IFD)/1130/2012-2013 SR/CSI/38/2011 (G) DST P07-520) New Delhi, India.

"Corresponding author.
}

\section{INTRODUCTION}

Parkinson's disease (PD) is the second most common neurodegenerative disease ranking next to Alzheimer's disease [1]. The loss of dopaminergic neurons in the Substantia nigra (SN) pars compacta results in the reduction of the level of dopamine in this region [2]. In modern medicine, Levodopa (L-dopa) is used as a dopamine supplement and provides effective treatment against the symptoms of PD [3]. Despite its wide usage, long term administration of L-dopa leads to motor complications called L-dopa induced dyskinesia (LIDS) [4]. Thus, the use of L-dopa as a therapy for PD is now being challenged due to its side effects and extensive research has been opened up for developing new and potent drugs for treating PD.

Recently, many epidemiological studies have validated the relationship between PD and environmental factors such as farming [5], drinking water from wells [6], agricultural chemicals, pesticides, and herbicides [7]. Notably, there are a number of pesticides including paraquat (PQ), rotenone and maneb (MB) that can be used to create animal models of PD and to study its mechanism and therapeutic interventions [8-10]. Despite the wide usage of these models, they have limitations to being perfect PD models [11]. As suggested by various studies, the PQ and MB induced PD model is considered to be the best due to the slow progression of the disease [12]. In addition, the generation of free radicals, mitochondrial dysfunctions, microglial activation, increased lipid peroxidation and nitric oxide levels are well documented in $\mathrm{PQ}+\mathrm{MB}$ intoxicated mice [13].

Mucuna pruriens Linn. (Mp) (Fabaceae), commonly known as Kapikacho or Kevach in Hindi, is used as a therapeutic drug in Ayurveda, the traditional medical 
system of India [14]. It is a climbing legume native to southern China and eastern India [15]. The seed, root and stem of Mp possess valuable medicinal properties [16]. It has been reported to contain analgesic, anti-neoplastic anti-inflammatory, anti-epileptic, anti-microbial and learning and memory enhancing properties $[17,18]$. Further, some studies, including those conducted in the present laboratory, have demonstrated Mp's potent neuroprotective properties in PQ-induced Parkinsonian mice [15]. Interestingly, Mp seed extract contains L-DOPA, the dopamine precursor that is used as a therapeutic agent against PD $[15,16]$. Although the antioxidative properties of Mp are well reported, the exact mechanism of Mp's antioxidative action remains unknown [19].

Withania somnifera (Ws) is regarded as the wonder shrub of Ayurveda, commonly found on the Indian subcontinent [20]. It is an important indigenous medicinal plant used for the treatment of many diseases including stress, insomnia, anxiety, arthritis and other disorders related to the central nervous system (CNS) such as PD and Alzheimer's disease [21]. Further, it has a significant role in the prevention and management of drug addiction [22,23]. Using a MPTP-induced PD mouse model, Ws was shown to have antioxidant and free radical scavenging potential [24]. Further, using a PQ model of PD in mice, our laboratory demonstrated the neuroprotective role of Ws [23].

The objective of the present work is to elucidate the synergistic neuroprotective effects of Ws root extract and $\mathrm{Mp}$ seed extract in PQ induced Parkinsonian mice. In the present study, the efficacy of Ws root extract and Mp seed extract in providing protection to dopamirnergic neurons against neurodegenaration caused by oxidative stress in the SN was examined. The neuro-protective activity of $\mathrm{Mp}$ and Ws was evaluated through the expression of tyrosine hydroxylase (TH) in the SN of PD mice and also the observation of improvements in motor coordination with narrow beam, hanging and rotarod tests.

\section{MATERIAL \& METHODS}

\subsection{Medicinal Plants and Preparation of Extracts}

Mp seed powder and Ws root powder were purchased from the Ayurveda Pharmacy, Institute of Medical Science, Banaras Hindu University, Varanasi. To prepare the ethanolic extract of the powdered material, $600 \mathrm{~g}$ of each were soaked separately in $1000 \mathrm{~mL}$ of ethanol overnight. The extracts were refluxed using a soxhlet apparatus and concentrated under reduced pressure. Finally the extracts were stored at $4^{\circ} \mathrm{C}$ and suspended in $0.7 \%$ carboxy methyl cellulose (CMC, S. D fine chemicals, India) for in vivo assays.

\subsection{Animal Treatment}

Male Swiss albino mice weighing $25 \pm 5 \mathrm{~g}$ were used in all experiments. Swiss albino mice were obtained from the animal house of the Institute of Medical Science, BHU, Varanasi, India. The study was approved by the Institutional Ethics Committee for use of laboratory animals and all the experimental procedures were performed under the national guidelines on the proper care and use of animals in laboratory research. Animals were maintained under standard conditions of temperature $\left(22^{\circ} \mathrm{C} \pm\right.$ $\left.5^{\circ} \mathrm{C}\right)$, humidity $(45 \%-55 \%)$ and light $(12: 12 \mathrm{~h}$ light: dark cycle). The animals were fed with a standard pellet diet and water ad libitum [25].

Animals were randomly divided into three experimental groups $(\mathrm{n}=6)$ as follows:

Group I: Control mice. Mice were administered intraperitoneal (i.p.) injections of saline ( $0.9 \%)$ per day.

Group II: Parkinsonian mice. Mice were administered i.p. injections of PQ (10 mg/kg body wt.) twice weekly for 9 weeks.

Group III: Treated Mice. In addition to the treatment given to Group II, animals were orally administered alcoholic seed extract of Mp (100 mg/kg) daily.

Group IV: Treated mice. In addition to PQ, animals were orally administered alcoholic root extract of Ws $(100 \mathrm{mg} / \mathrm{kg})$ daily.

Group V: Treated mice. In addition to $\mathrm{PQ}$, animals were orally administered alcoholic seed extract of Mp $(50 \mathrm{mg} / \mathrm{kg})$ [26] and alcoholic root extract of Ws $(48 \mathrm{mg} /$ $\mathrm{kg})$ [27] daily.

PQ was obtained from Sigma Aldrich (St. Louis, Mo, USA). All the above treatments were carried out for 9 weeks to check disease development and the effect on its treatment. At the end of the experiment, behavioural studies were performed to understand motor skill abnormalities.

\subsection{Neurobehavioral Parameters}

\subsubsection{Hanging Test}

The hanging test was performed as previously described by Mohanasundari et al. [28]. Briefly, mice were placed on a horizontal grid and inverted upside down. The mice were allowed to hang by gripping the grid and the time it took for the mice to fall (hanging time) was recorded for all the treatment groups separately.

\subsubsection{Narrow Beam Walking Test}

The narrow beam walking test was performed as previously described by Pisa [29]. In brief, a narrow flat beam was placed at a height of $100 \mathrm{~cm}$ from the floor and mice were trained to walk on it. Following training, the mice were tested by recording the time it took to cross the beam. This measure is used to assess the motor coordina- 
tion of the experimental groups.

\subsubsection{Rotarod Test}

The rotarod test was performed to measure the muscular coordination skills of mice. In this test, the beam revolves around its longitudinal axis and the mice walk or run forward in synchrony. Mice were trained for 3 consecutive days before the day of final treatment at a fixed speed for 5 minutes. Mice adjust their posture in response to a moving speed of $5 \mathrm{rpm}$ and the time it took for the mice to fall from the rotarod was recorded. An average of four experimental readings was calculated for each animal [30].

\subsection{Biochemical Parameters}

\subsubsection{Lipid Peroxidation}

Lipid peroxidation in the nigrostraital tissue of the mouse brain was estimated according to the method described previously [31] with slight modifications. Briefly, in order to measure the concentration of malondialdehye (MDA) an assay mixture containing 10\% tissue homogenate $(0.1 \mathrm{~mL})$ was mixed with $10 \%$ SDS solution $(0.1$ $\mathrm{mL}$ ) and incubated for 5 minutes at room temperature followed by the addition of $20 \%$ acetic acid $(0.6 \mathrm{~mL})$ and further incubation for 2 - 5 minutes. Finally $0.8 \%$ Thiobarbituric acid TBA $(0.6 \mathrm{~mL})$ was added and the reaction mixture was incubated in a boiling water bath for $1 \mathrm{hr}$. The assay mixture was cooled, centrifuged and absorbance of the supernatant was read at $532 \mathrm{~nm}$ against control. LPO levels are expressed as nano moles MDA/mg protein.

\subsubsection{Nitrite Estimation}

Nitrite was estimated in the tissue homogenate supernatant as previously described by [32]. Briefly, supernatant of $10 \% \mathrm{w} / \mathrm{v}$ tissue homogenate was incubated with ammonium chloride $(0.7 \mathrm{mM})$ followed by addition of Griess reagent $(0.1 \% \mathrm{~N}$-naphthylethylenediamine and $1 \%$ sulfanilamide in $2.5 \%$ phosphoricacid). The reaction mixture was incubated for 30 minutes at $37^{\circ} \mathrm{C}$ and the absorbance was measured at $540 \mathrm{~nm}$. The nitrite content was calculated using a standard curve for sodium nitrite $(10-100 \mu \mathrm{M})$ in units of $\mu$ moles $/ \mathrm{ml}$.

Following behavioural and biochemical tests further experiments were conducted only with control, PQ and, $\mathrm{Mp}+\mathrm{Ws}$ and PQ co-treated groups.

\subsubsection{Immunoreactivity}

Immunohistochemical (IHC) staining of tyrosine hydroxylase (TH)-positive cells in dopaminergic (DAergic) neurons was performed in mice brain sections of control and treated groups using a standard procedure [33]. Briefly, perfused mouse brains were post-fixed with para- formaldehyde and cryoprotected in sucrose. Following this, the brain was cut into $20 \mu \mathrm{m}$ sections using a cryostat. Sections were washed with PBS and incubated in blocking buffer $1\left(0.5 \% \mathrm{H}_{2} \mathrm{O}_{2}\right.$ in methanol and PBS) for 15 minutes, to block endogenous peroxidase activity, followed by incubation in Blocking Buffer 2 (2\% normal goat serum, in PBS) for $2 \mathrm{hr}$ and washed again. The sections were then incubated with a primary monoclonal anti-TH antibody (dilution 1:1000, Santa Cruz, USA) at $4^{\circ} \mathrm{C}$ for $48 \mathrm{hr}$ and washed again. The sections were incubated with a biotinylated secondary antibody (Merck, dilution 1:500) for $2 \mathrm{hr}$ and subsequently treated with a streptavidin peroxidase complex for $30 \mathrm{~min}$. The colour was developed with 3, 3 diaminobenzidine and the sections were permanently mounted with dextrenepthylate xylene (DPX) after dehydration in graded ethanol, as described previously [34]. The mounted sections were examined under bright field microscopy (Nikon, Japan Tokyo, bright field microscope) and images were captured at $10 \times$ magnification. Counting of TH-positive cells was done using a standard procedure as described previously by [35].

\subsubsection{Western Blotting}

Western blot analysis was done as described previously [36]. Briefly, a 10\% w/v tissue homogenate was made in lysis buffer (20 mM Tris- $\mathrm{HCl}, \mathrm{pH}$ 7.4, 2 mM EDTA, 2 mM EGTA, $1 \mathrm{mM}$ PMSF, $30 \mathrm{mM} \mathrm{NaF}, 30 \mathrm{mM}$ sodium pyrophosphate, $0.1 \%$ SDS, $1 \%$ Triton X-100 and protease inhibitor cocktail). Protein content was measured using a standard Bradford Assay [37]. The proteins (80 $90 \mathrm{~g})$ were separated on a $12 \%$ SDS-PAGE and electroblotted onto a PVDF membrane. The membrane was incubated with mouse monoclonal antibodies for $\mathrm{TH}$ or $\beta$-actin (Santa crutz, USA; dilution 1:500) in Tris-buffered saline (TBS, pH 7.4) containing 5\% non-fat dry milk, overnight at $4^{\circ} \mathrm{C}$. The blot was washed three times with TBS containing $0.2 \%$ Tween- 20 to remove unbound antibodies. The blot was further incubated with goat antimouse IgG peroxidase conjugate (1:2000 dilution) for 2 $\mathrm{hr}$ at room temperature. The blot was washed three times with $\mathrm{TBS}$ and developed with $\mathrm{TMB} / \mathrm{H}_{2} \mathrm{O}_{2}$ western blot kits (Bangalore Genei, India). Finally, the developed blots were subjected to densitometric analysis using $\beta$-actin as an internal control.

\subsection{Statistical Analysis}

Statistical analysis of the data was performed using oneway analysis of variance (ANOVA) using Graph Pad Instat software. Data were expressed as mean \pm standard error mean (SEM) for separate groups. The significance of the data was evaluated by using Tukey's post hoc analyses and differences were considered statistically 
significant, when $\mathrm{p}$ values were less than $0.05(\mathrm{p}<0.05)$.

\section{RESULTS}

\subsection{Effect of Mp + Ws on Behavioural Parameters in PD Mice}

Hanging time measures motor function in mice. Compared to controls, the hanging time of PQ treated mice was significantly reduced. Co-administration of $\mathrm{Mp}+$ Ws seed extract to the PD mice significantly improved motor function compared to $\mathrm{Mp}$ and $\mathrm{Ws}$ alone, as the hanging time was extended to the level of controls (Figure 1).

Additionally, the number of narrow beam walking errors was increased in the PQ treated mice as compared to controls. Treatment with $\mathrm{Mp}+\mathrm{Ws}$ decreased the number of walking errors compared to the PD mouse model. This improvement was found to be significantly better compared to individual treatment of $\mathrm{Mp}$ and Ws (Figure 2).

In rotarod test, animals walk on a rotating drum and their performance is measured by the duration in seconds that the animal remains on the rotating drum. The motor coordination in Parkinsonian mice was greatly compromised, but it was protected significantly by the pretreatment with $\mathrm{Mp}+\mathrm{Ws}$ which was better than Mp and Ws alone (Figure 3).

\subsection{Effect of Mp + Ws on Lipid Peroxidation and Nitrite Levels}

To investigate the extent of lipid peroxidation occurring in the nigrostriatal region of brain of PQ treated mice, the level of MDA was examined. Compared to controls, MDA levels were significantly elevated in the PD modelled mice. Co-treatment of PD mice with Mp + Ws significantly reduced the elevated levels of MDA which was found to be better than Mp and Ws alone (Figure 4).

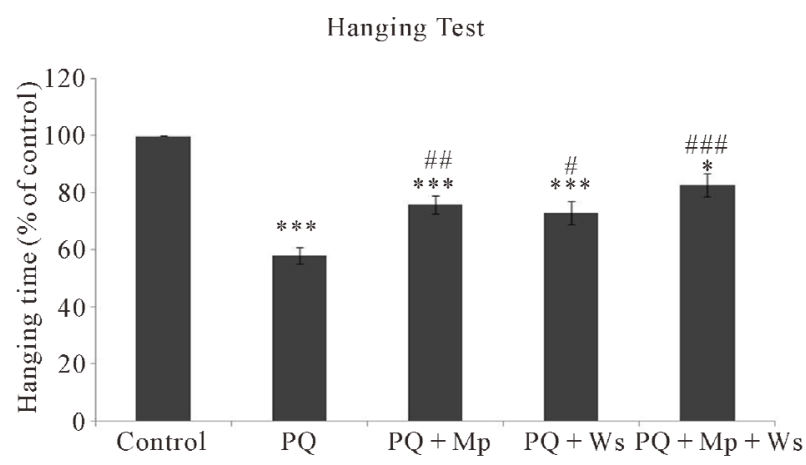

Figure 1. Effect of $\mathrm{Mp}+\mathrm{Ws}$ on hanging time against PQ induced PD phenotype in mouse. Data is expressed in term of mean \pm SEM $(n=6)$, significant changes are given as ${ }^{*} \mathrm{p}<$ $0.05)$, and ${ }^{* * *} \mathrm{p}<0.001$ as compared to control, ${ }^{\#} \mathrm{p}<0.05,{ }^{\# \#} \mathrm{p}$ $<0.01)$ and ${ }^{\# \#} \mathrm{p}<0.001$ compared to PQ treated group.
Narrow beam walking Test

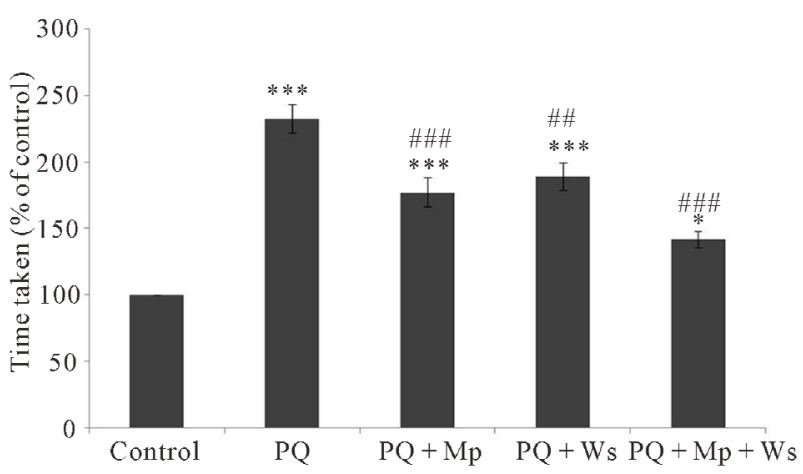

Figure 2. Effect of $\mathrm{Mp}+\mathrm{Ws}$ on narrow beam walking test against PQ induced PD phenotype in mouse. Data is expressed in term of mean \pm SEM $(n=6)$, significant changes are given as ${ }^{*}$ p $<0.05$ and ${ }^{* * *}$ p $<0.001$ as compared to control, ${ }^{\# \#}$ p $<0.01$ and ${ }^{\# \# \#} \mathrm{p}<0.001$ as compared with PQ treated group.

Rotarod Test

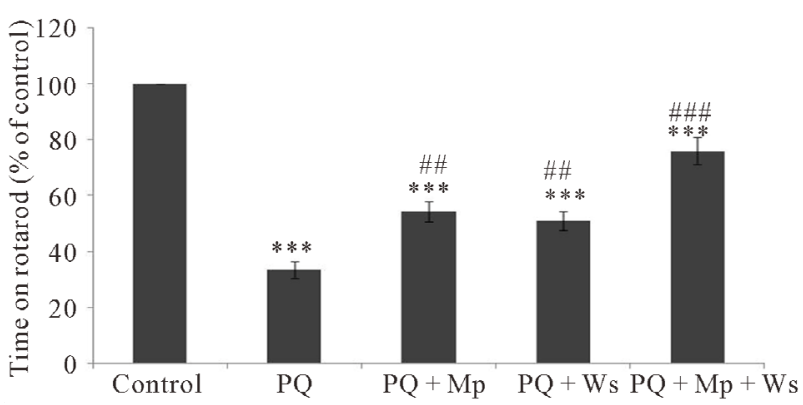

Figure 3. Effect of $\mathrm{Mp}+\mathrm{Ws}$ on rotarod test against PQ induced PD phenotype in mouse. Data is expressed in term of mean \pm SEM $(n=6)$, significant changes are given as ${ }^{* * *} p<$ 0.001 as compared to control, ${ }^{\#}$ p $<0.01$ and ${ }^{\# \#}$ p $<0.001$ as compared with PQ treated group.

Similarly, the administration of PQ increased nitrite levels in the nigrostriatum region of PD mice, compared to controls. Treatment of PQ afflicted mice with Mp + Ws significantly reduced the elevated levels of nitrites and was found to be significantly better than Mp and Ws alone (Figure 5).

\subsection{TH-Immunohistochemistry}

IHC analysis of TH-positive DAergic neurons in frozen brain sections was conducted to evaluate the effect of Mp + Ws on PQ treated mice. PQ treatment led to a significant decline in the $\mathrm{TH}$ positive neurons, whereas cotreatment of mice with $\mathrm{Mp}+\mathrm{Ws}$ led to a significant increase in TH-positive DAergic neurons in the SN region, which was comparable to controls (Figures 6(a) and (b)). The improvement in the $\mathrm{Mp}+\mathrm{Ws}$ treated group was expressed in terms of number of TH positive cells in the $\mathrm{SN}$ region. 
Lipid peroxidation

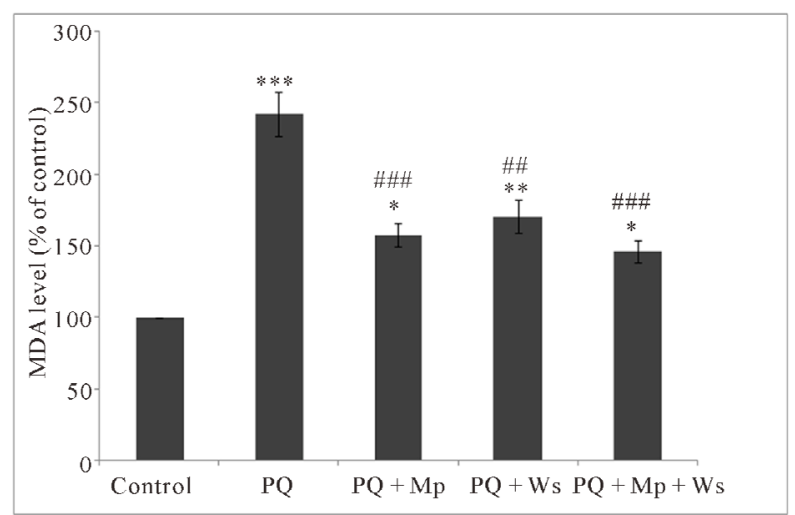

Figure 4. Effect of $\mathrm{Mp}+\mathrm{Ws}$ on MDA levels on the PQ induced PD phenotype in mice. Data is expressed in terms of mean \pm SEM $(n=6)$, significant changes are given as ${ }^{*} p<0.05$, ${ }^{* *} \mathrm{p}<0.01$ and ${ }^{* * *} \mathrm{p}<0.001$ compared to control, ${ }^{\# \#} \mathrm{p}<0.01$ and $\#$ p $<0.001$ compared with PQ treated group.

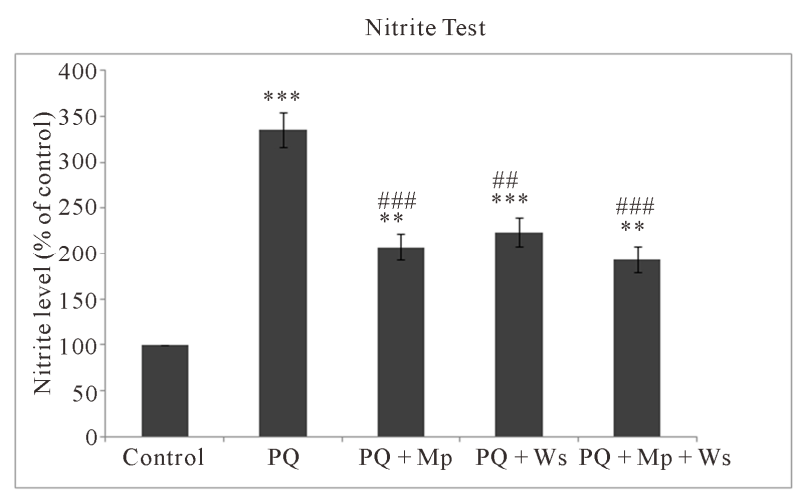

Figure 5. Effect of $\mathrm{Mp}+\mathrm{Ws}$ on nitrite levels on the PQ induced PD phenotype in mice. Data is expressed in terms of mean \pm SEM $(\mathrm{n}=6)$, significant changes are given as ${ }^{* *} \mathrm{p}<$ 0.01 and ${ }^{* * *} \mathrm{p}<0.001$ compared with control and ${ }^{\# \#} \mathrm{p}<0.01$ and $\#$ \#\# $<0.001$ compared with PQ treated group.

\subsection{Western Blotting}

The effect of Mp + Ws on TH expression in the SN region of mice was validated by western blotting. TH expression was reduced in PQ treated mice and was significantly recovered after treatment with $\mathrm{Mp}+\mathrm{Ws}$. The determined TH level was evaluated through Image $\mathrm{J}$ software and integrated density related to $\beta$-actin was calculated (Figures 7(a) and (b)).

\section{DISCUSSION}

The present study aims to reveal the synergistic effect of two important medicinal plants in Ayurveda medicine, namely Mucunae pruriens (Mp) and Withania somnifera (Ws). This study shows that the coordinated treatment of $\mathrm{Mp}$ together with Ws improves many of the symptoms of $\mathrm{PD}$ in a paraquat $(\mathrm{PQ})$ induced model of $\mathrm{PD}$ mice.

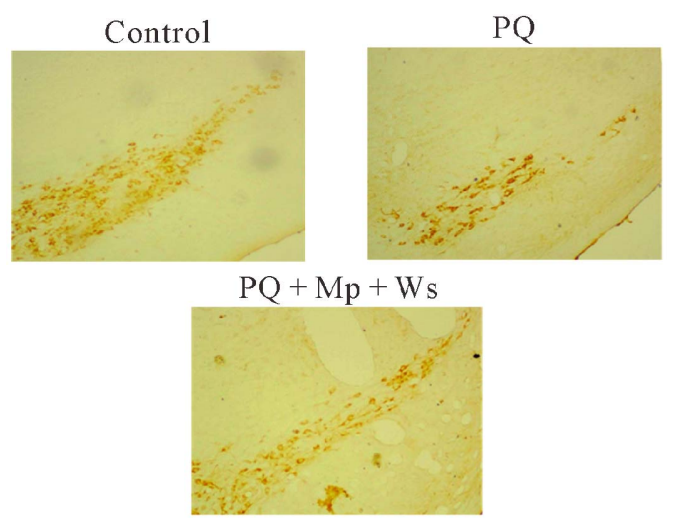

(a)

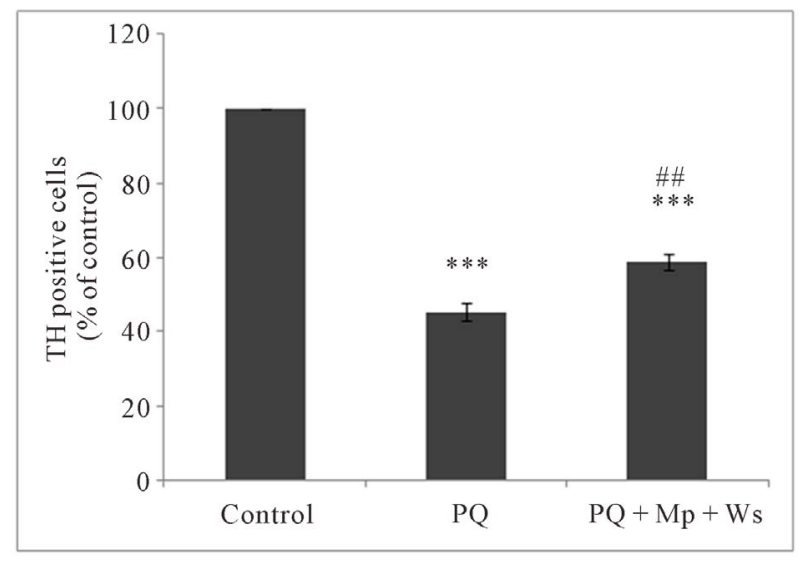

(b)

Figure 6. Effect of $\mathrm{Mp}+\mathrm{Ws}$ on $\mathrm{TH}$ immunoreactivity in the $\mathrm{SN}$ region of mice brain following exposure to PQ. (a) Representative TH immunoreactivity in frozen brain sections of control and treated animals; (b) Number of TH positive neurons in $\mathrm{SN}$ region of control and treated groups. Data is expressed in terms of mean \pm SEM $(n=6)$. Significant changes are indicated by ${ }^{* * *} \mathrm{p}<0.001$ compared with control, ${ }^{\# \#} \mathrm{p}<0.01$ compared to PQ treated group.

Pesticides have been implicated as one of the major risk factors for PD [38]. Using different animal models, it has been demonstrated that exposure to pesticides during development could produce progressive, permanent and cumulative neurotoxicity of the nigrostriatal system, which enhances vulnerability to subsequent environmental insults [39].

PQ is a well-known pesticide that is used in experimental mice models to develop a slow and progressive neurodegenerative disorder that emulates the symptoms of PD $[38,40]$. PQ selectively damages the dopaminergicnigrostriatal system, resulting in the loss of dopaminergic neurons in the Substantia nigra (SN). This loss can also be accompanied by a decrease in dopamine levels in the SN [41]. PQ selectively and synergistically targets the nigrostriatal system leading to a significant reduction in motor activity, degeneration of dopaminer- 


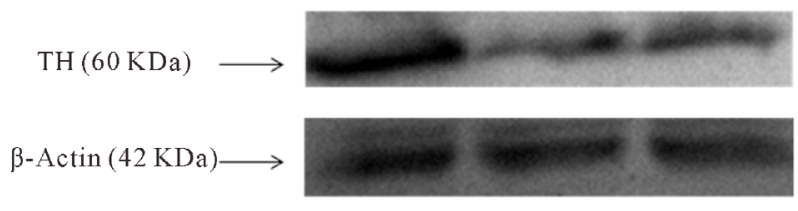

(a)

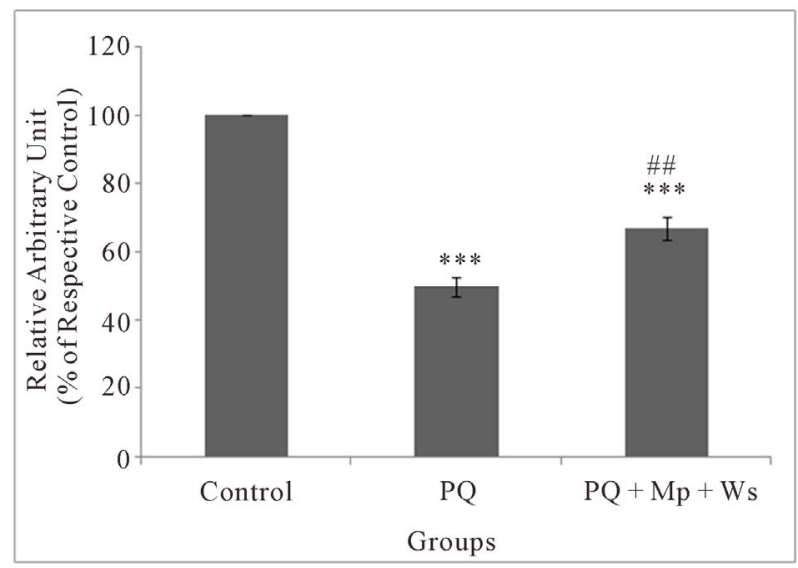

(b)

Figure 7. Effect of Mp + Ws on expression levels of TH in the $\mathrm{SN}$ region of mice brains following exposure to PQ. (a) Representative western blot analysis; (b) Determined TH level is expressed as the integrated density as related to $\beta$-actin. Data is expressed in terms of mean \pm SEM $(n=6)$. Significant changes are indicated by ${ }^{* * *} \mathrm{p}<0.001$ compared with control and ${ }^{\# \#} \mathrm{p}<$ 0.01 compared to PQ treated group.

gic neurons, neuronal toxicity, increase in oxidative stress and lipid peroxidation $[12,40,42]$. As the regenerative capacity of neurons is very low, the brain is believed to be highly susceptible to the damaging effects of reactive oxygen species (ROS) [43].

Oxidative stress is considered to be one of the key factors in the pathogenesis of PD [44]. PQ itself is an oxidant as it forms a PQ radical that transfers its extra electron to an oxygen molecule generating a superoxide anion [45]. Such a superoxide anion gets converted to hydrogen peroxide that subsequently turns into either a harmful hydroxyl radical or is directly detoxified by antioxidant enzymes [46]. Hydroxyl radicals along with other free radicals react with polyunsaturated fatty acids to yield lipid hydro-peroxides. These products initiate the lipid radical chain reaction leading to oxidative damage. Malondialdehyde (MDA), a product of lipid peroxidation, is used as a marker of oxidative damage [23]. After treatment of mice with PQ, the MDA level was significantly increased compared to controls. However, MDA levels were significantly ameliorated when mice received $\mathrm{Mp}+\mathrm{Ws}$ co-treatment. Moreover, it was found that the combined treatment of $\mathrm{Mp}+\mathrm{Ws}$ showed a significant effect compared to $\mathrm{Mp}$ and $\mathrm{Ws}$ alone.

In addition, the present study demonstrates that exposure to $\mathrm{PQ}$ increases nitrite content in the nigrostriatal region, which is in accordance to earlier studies [13]. The co-exposure to $\mathrm{Mp}+\mathrm{Ws}$ amends the level of nitrite in PQ treated mice. The decline in nitrite content by $\mathrm{Mp}+$ Ws might be attributed to the antioxidant property of these plant extracts $[15,47]$. These results are in harmony with other reports of herbal drug mediated neuroprotection $[23,48]$.

In addition to oxidative stress, PQ selectively damages the dopaminergic nigrostriatal system, resulting in the loss of dopaminergic neurons in the SN [41]. The results obtained in the present study also suggest selective dopaminergic neuronal loss following exposure to PDinducing neurotoxins, which is in harmony with previous studies $[49,50]$. The functionality of dopaminergic neurons can be measured by the presence of tyrosine hydroxylase $(\mathrm{TH})$, an enzyme that converts dopamine's precursor, L-Dopa, into dopamine itself. In the present study, TH-immunoreactivity was significantly reduced in PQ treated mice. These results were validated by western blotting, which showed a similar pattern of reduction in $\mathrm{TH}$ content. Both techniques also demonstrated that PD mice co-treated with $\mathrm{Mp}+\mathrm{Ws}$ had a significantly increased level of TH-positive neurons compared to the PQ treated PD mice. This increase is probably due to the combined antioxidant action of Ws [51] and L-dopa content of Mp [52].

A battery of behavioural tests was conducted to assess the motor functionality of the PD modelled mice. These tests (narrow beam walking, hanging and rotarod tests), demonstrated impaired motor functioning in PQ treated mice, similar to PD patients. It was observed that PD modelled mice treated with $\mathrm{Mp}+\mathrm{Ws}$ had improved hanging time, and reduced time to cross the narrow beam. In addition, the rotarod test is widely used to assess motor coordination skill of animals. Over the years, this task has been used by various researchers and it has proven to be very informative regarding the qualitative aspect of walking movements in animals [53]. In the present study, PD modeled animals consistently preformed more poorly than controls in the rotarod test and co-treatment with $\mathrm{Mp}+\mathrm{Ws}$ significantly rescued this impairment.

The present study gives strong evidence for the beneficial effect of the co-administration of $\mathrm{Mp}+\mathrm{Ws}$ on PDrelated symptoms in PQ induced Parkinsonian mice. In combination, these herbal plants show effective neuroprotective activity. Together, they successfully attenuate PQ induced neurotoxicity, which is evident from the improved level of $\mathrm{TH}$ activity in $\mathrm{SN}$ region of mice brain indicating rescued levels of dopamine. The behavioural and antioxidant recovery is also a substantial indicator of the neuroprotective action of these herbal plants.

\section{ACKNOWLEDGEMENTS}

Authors are thankful to Miss. Susan Westfall, Douglas Mental Health 
University Institute, Montreal, QC, Canada and Department of Neurology and Neurosurgery, McGill University, Montreal, QC, Canada for her constructive suggestions while writing the paper. Authors wish to acknowledge Dr. T. D. Singh, Associate Professor, Department of Medicinal Chemistry, IMS, BHU, for helping us to prepare ethanolic root extract of Ws in his laboratory. The authors sincerely thank Indian Council of Medical Research (ICMR), New Delhi, India for providing research fellowship to Jay Prakash, Council of Scientific and Industrial Research (CSIR), New Delhi, India for providing research fellowship to Satyndra Kumar Yadav and Department of Science and Technology (DST), New Delhi, India for providing fellowship to Shikha Chouhan.

\section{REFERENCES}

[1] Dauer, W. and Przedborski, S. (2003) Parkinson's disease: Mechanisms and models. Neuron, 39, 889-909. http://dx.doi.org/10.1016/S0896-6273(03)00568-3

[2] Singh, C., Ahmad, I. and Kumar, A. (2007) Pesticides and metals induced Parkinson's disease: involvement of free radicals and oxidative stress. Cell and Molecular Biology, 30, 19-28.

[3] Maheswari, T., Vijayraja, D., Kundhavai, N.R., Kalaivani, K., Rajasankar, S., Tamilselvama, K. and Manivasagama, T. (2010) Synergistic neuropreventive effect of Withania somnifera root powder and Mucuna pruriens seed powder in parkinsonic mice model. Journal of Herbal Medicine and Toxicology, 4, 63-69.

[4] Borah, A. and Mohanakumar, K.P. (2012) L-DOPA induced-endogenous 6-hydroxydopamine is the cause of aggravated dopaminergic neurodegeneration in Parkinson's disease patients. Medical Hypotheses, 79, 271-273. http://dx.doi.org/10.1016/j.mehy.2012.05.008

[5] Cannon, J.R. and Greenamyre, J.T. (2011) The role of environmental exposures in neurodegeneration and neurodegenerative diseases. Toxicological Sciences, 124, 225250. http://dx.doi.org/10.1093/toxsci/kfr239

[6] Gatto, N.M., Cockburn, M., Bronstein, M.A.D. and Ritz, B. (2009) Well-water consumption and Parkinson's disease in rural California. Environmental Health Perspectives, 117, 1912-1918.

[7] Semchuk, K.M., Love, E.J. and Lee, R.G. (1992) Parkinson's disease and exposure to agricultural work and pesticide chemicals. Neurology, 42, 1328-1335. http://dx.doi.org/10.1212/WNL.42.7.1328

[8] Duty, S. and Jenner, P. (2011) Animal models of Parkinson's disease: A source of novel treatments and clues to the cause of the disease. British Journal of Pharmacology, 164, 1357-1391. http://dx.doi.org/10.1111/j.1476-5381.2011.01426.x

[9] Singh, S., Singh, K., Patel, S., Patel, D.K., Singh, C., Nath, C. and Singh, M.P. (2008) Nicotine and caffeinemediated modulation in the expression of toxicant responsive genes and vesicular monoamine transporter- 2 in 1-methyl 4-phenyl-1,2,3,6-tetrahydropyridineinduced Parkinson's disease phenotype in mouse. Brain Research, 1207, 193-206. http://dx.doi.org/10.1016/j.brainres.2008.02.023
[10] Yadav, S., Dixit, A., Agrawal, S., Singh, A., Srivastava, G., Singh, A.K., Srivastava, P.K., Prakash, O. and Singh, M.P. (2012) Rodent models and contemporary molecular techniques: Notable feats yet incomplete explanations of Parkinson's disease pathogenesis. Molecular Neurobiology, 46, 495-512. http://dx.doi.org/10.1007/s12035-012-8291-8

[11] Tiwari, M.N., Singh, A.K., Ahmad, I., Upadhyay, G., Singh, D., Patel, D.K., Singh, C., Prakash, O. and Singh, M.P. (2010) Effects of cypermethrin on monoamine transporters, xenobiotic metabolizing enzymes and lipid peroxidation in the rat nigrostriatal system. Free Radical Research, 44, 1416-1424. http://dx.doi.org/10.3109/10715762.2010.512041

[12] Patel, S., Singh, V., Kumar, A. Gupta, Y.K. and Singh, M.P. (2006) Status of antioxidant defence system and expression of toxicant responsive genes in striatum of maneb- and paraquat induced Parkinson's disease phenotype in mouse: mechanism of neurodegeneration. Brain Research, 1081, 9-18. http://dx.doi.org/10.1016/j.brainres.2006.01.060

[13] Gupta, S.P., Patel, S., Yadav, S., Singh, A.K., Singh, S. and Singh, M.P. (2010) Involvement of nitric oxide in Maneb and paraquat-induced Parkinson's disease phenotype in mouse: Is there any link with lipid peroxidation. Neurochemical Research, 35, 1206-1213. http://dx.doi.org/10.1007/s11064-010-0176-5

[14] Ngatchic, J.T., Sokeng, S.D., Njintang, N.Y., Maoundombaye, T., Oben, J. and Mbofung, C.M. (2013) Evaluation of some selected blood parameters and histopathology of liver and kidney of rats fed protein-substituted mucuna flour and derived protein rich product. Food and Chemical Toxicology, 57, 46-53.

http://dx.doi.org/10.1016/j.fct.2013.02.045

[15] Yadav, S.K., Prakash, J., Chouhan, S. and Singh, S.P. (2013) Mucuna pruriens seed extract reduces oxidative stress in nigrostriatal tissue and improves neurobehavioral activity in paraquat-induced Parkinsonian mouse model. Neurochemistry International, 62, 1039-1047. http://dx.doi.org/10.1016/j.neuint.2013.03.015

[16] Suresh, S., Prithiviraj, E., Lakshmi, N.V., Ganesh, M.K., Ganesh, L. and Prakash, S. (2012) Effect of Mucunapruriens (Linn.) on mitochondrial dysfunction and DNA damage in epididymal sperm of streptozotocin induced diabetic rat. Journal of Ethnopharmacology, 145, 32-41. http://dx.doi.org/10.1016/j.jep.2012.10.030

[17] Adepoju, G.K.A. and Odubena, O.O. (2009) Effect of Mucuna pruriens on some haematological and biochemical parameters. Journal of Medicinal Plants Research, 3, 73-76.

[18] Sathiyanarayanan, L. and Arulmozhi, S. (2007) Mucunapruriens L. A comprehensive review. Pharmacognosy Reviews, 1, 157-162.

[19] Tripathi, Y.B. and Upadhyay, A.K. (2001) Antioxidant property of Mucuna pruriens L. Current Science, 80, 1-11.

[20] Widodo, N., Kaur, K., Shrestha, B.G., Takagi, Y., Ishii, T., Wadhwa, R. and Kaul S.C. (2007) Selective killing of cancer cells by leaf extract of Ashwagandha: Identification of a tumor-inhibitory factor and the first molecular 
insights to its effect. Clinical Cancer Research, 13, 22982306. http://dx.doi.org/10.1158/1078-0432.CCR-06-0948

[21] Kataria, H., Wadhwa, R. and Kaul, S.C. (2013) Withaniasomnifera water extract as a potential candidate for differentiation based therapy of human neuroblastomas. PLoS One, 8, e55316.

http://dx.doi.org/10.1371/journal.pone.0055316

[22] Kulkarni, S.K. and Dhir, A. (2008) Withaniasomnifera: An Indian ginseng. Progress in Neuro-Psychopharmacology \& Biological Psychiatry, 32, 1093-1105.

[23] Prakash, J., Yadav, S.K., Chouhan, S. and Singh, S.P. (2013) Neuroprotective role of Withaniasomnifera root extract in maneb-paraquat induced mouse model of Parkinsonism. Neurochemical Research, 38, 972-980. http://dx.doi.org/10.1007/s11064-013-1005-4

[24] Rajasankara, S., Manivasagam, T., Sankar, V., Prakash, S., Muthusamy, R., Krishnamurti, A. and Surendran, S. (2009). Withaniasomnifera root extract improves catecholamines and physiological abnormalities seen in a Parkinson's disease model mouse. Journal of Ethnopharmacology, 125, 369-373. http://dx.doi.org/10.1016/j.jep.2009.08.003

[25] Chouhan, S., Prakash, J., Yadav, S.K., Agrawal, N.K. and Singh, S.P. (2013) Effect of bisphenol A on fertility of male mice. Journal of Scientific Research, 57, 77-84.

[26] Bhattacharya, A., Ghosal, S. and Bhattacharya, S.K. (2001) Anti-oxidant effect of Withaniasomniferaglycowithanolides in chronic footshock stress-induced perturbations of oxidative free radical scavenging enzymes and lipid peroxidation in rat frontal cortex and striatum. Journal of Ethnopharmacology, 74, 1-6. http://dx.doi.org/10.1016/S0378-8741(00)00309-3

[27] Kasture, S., Pontis, S., Pinna, A., Schintu, N., Spina, L., Longoni, R., Simola N., Ballero M. and Morelli, M. (2009) Assessment of symptomatic and neuroprotective efficacy of Mucuna pruriens seed extract in rodent model of Parkinson's disease. Neurotoxicity Research, 15, 111-122. http://dx.doi.org/10.1007/s12640-009-9011-7

[28] Mohanasundari, M., Srinivasan, M.S., Sethupathy, S. and Sabesan, M. (2006) Enhanced neuroprotective effect by combination of bromocriptine and Hypericumperforatum extract against MPTP-induced neurotoxicity in mice. Journal of the Neurological Sciences, 249, 140-144. http://dx.doi.org/10.1016/j.jns.2006.06.018

[29] Pisa, M. (1998) Regional specialization of motor functions in the rat striatum: implications for the treatment of Parkinsonism. Progress in Neuro-Psychopharmacology \& Biological Psychiatry, 12, 217-224.

[30] Manna, S., Bhattacharyya, D., Mandal, T.K. and Dey, S. (2006) Neuropharmacological effects of deltamethrin in rats. Journal of Veterinary Science, 7, 133-136. http://dx.doi.org/10.4142/jvs.2006.7.2.133

[31] Ohkawa, H., Ohishi, N. and Yag, K. (1979) Assay for lipid peroxides in animal tissues by thiobarbituric acid reaction. Analytical Biochemistry, 95, 351-358. http://dx.doi.org/10.1016/0003-2697(79)90738-3

[32] Granger, D.L., Taintor, R.R., Boockvar, K.S. and Hibbs, J.B. (1996) Measurement of nitrate and nitrite in biologi- cal samples using nitrate reductase and Greiss reaction. Methods in Enzymology, 268, 142-151. http://dx.doi.org/10.1016/S0076-6879(96)68016-1

[33] Gorbatyuk, O.S., Li, S., Sullivan, L.F., Chen, W., Kondrikova, G., Manfredsson, F.P., Mandel, R.J. and Muzyczka, N. (2008) The phosphorylation state of Ser-129 in human alpha-synuclein determines neurode-generation in a rat model of Parkinson disease. Proceedings of the National Academy of Sciences of the USA, 105, 763-768. http://dx.doi.org/10.1073/pnas.0711053105

[34] Singh, S., Singh, K., Patel, D.K., Singh, C., Nath, C., Singh, V.K., Singh, R.K. and Singh, M.P. (2009) The expression of CYP2D22, an ortholog of human CYP2D6, in mouse striatum and its modulation in 1-methyl 4-phenyl1,2,3,6-tetrahydropyridine induced Parkinson's disease phenotype and nicotine mediated neuroprotection. Rejuvenation Research, 12, 185-197. http://dx.doi.org/10.1089/rej.2009.0850

[35] Mochizuki, H., Hayakawa, H., Migit, M., Shibata, M., Tanaka, R., Suzuki, A., Shimo, N.Y., Urabe, T., Yamada, M., Tamayos, K., Shimada, T., Miura, M. and Mizuno, Y. (2001) An AAV-derived apaf-1 dominant negative inhibitor prevents MPTP toxicity as antiapoptotic gene therapy for Parkinson's disease. Proceedings of the $\mathrm{Na}$ tional Academy of Sciences of the USA, 98, 10918-10923. http://dx.doi.org/10.1073/pnas.191107398

[36] Martin, P.Y., Bianchi, M., Roger, F., Niksic, L., and Féraille, E. (2002) Arginine vasopressin modulates expression of neuronal NOS in rat renal medulla. American Journal of Physiology, 283, 559-568.

[37] Bradford, M.M. (1976) A rapid and sensitive method for the quantitation of microgram quantities of protein utilizing the principle of protein-dye binding. Analytical Biochemistry, 72, 248-254. http://dx.doi.org/10.1016/0003-2697(76)90527-3

[38] Mccormack, A.L., Thiruchelvam, M., Manning-Bog, A.B., Thiffault, C., Langston, J.W., Cory-Slechta, D.A., and Di Monte, D.A. (2002) Environmental risk factors and Parkinson's disease: Selective degeneration of nigral dopaminergic neurons caused by the herbicide paraquat. Neurobiology of Disease, 10, 119-127. http://dx.doi.org/10.1006/nbdi.2002.0507

[39] Cory-Slechta, D.A., Thiruchelvam, M., Barlow, B.K. and Richfield, E.K. (2005) Developmental pesticide models of the Parkinson disease phenotype. Environmental Health Perspectives, 113, 1263-1270. http://dx.doi.org/10.1289/ehp.7570

[40] Thiruchelvam, M., Brockel, B.J., Richfield, E.K., Baggs, R.B., and Cory-Slechta, D.A. (2000) Potentiated and preferential effects of combined paraquat and maneb on nigrostriatal dopamine systems: Environmental risk factors for Parkinson's disease? Brain Research, 873, 225-234. http://dx.doi.org/10.1016/S0006-8993(00)02496-3

[41] Kumar, A., Ahmad, I., Shukla, S., Singh, B.K., Patel, D.K., Pandey, H.P, and Singh, C. (2010) Effect of zinc and PQ co-exposure on neurodegeneration: Modulation of oxidative stress and expression of metallothioneins, toxicant responsive and transporter genes in rats. Free Radical Research, 44, 950-965. 
[42] Patel, S., Singh, K., Singh, S. and Singh, M.P. (2008) Gene expression profiles of mouse striatum in control and maneb+paraquat-induced Parkinson's disease phenotype: Validation of differentially expressed energy metabolizing transcripts. Molecular Biotechnology, 40, 59-68. http://dx.doi.org/10.1007/s12033-008-9060-9

[43] Uttara, B., Singh, A.V., Zamboni, P. and Mahajan, R.T. (2009) Oxidative stress and neurodegenerative diseases: A review of upstream and downstream antioxidant therapeutic options. Current Neuropharmacology, 7, 65-74. http://dx.doi.org/10.2174/157015909787602823

[44] Farooqui, T. and Farooqui, A.A. (2011) Lipid-mediated oxidative stress and inflammation in the pathogenesis of Parkinson's disease. Parkinson's Disease, 2011, 1-9.

[45] Kappus, H. (1986) Overview of enzyme systems involved in bioreduction of drugs and in redox cycling. Biochemical Pharmacology, 35, 1-6. http://dx.doi.org/10.1016/0006-2952(86)90544-7

[46] Beckman, J.S., Beckman, T.W., Chen, J., Marshall, P.A., and Freeman, B.A. (1990) Apparent hydroxyl radical production by peroxynitrite: Implications for endothelial injury from nitric oxide and superoxide. Proceedings of the National Academy of Sciences of the USA, 87, 1620-1624. http://dx.doi.org/10.1073/pnas.87.4.1620

[47] Bhatnagar, M., Sharma, D. and Salvi, M. (2009) Neuroprotective effects of Withaniasomniferadunal: A possible mechanism. Neurochemical Research, 34, 1975-1983. http://dx.doi.org/10.1007/s11064-009-9987-7

[48] Yadav, S., Gupta, S.P., Srivastava, G., Srivastava, P.K., and Singh, M.P. (2011) Role of secondary mediators in caffeine-mediated neuroprotection in maneb- and para- quat-induced Parkinson's disease phenotype in the mouse. Neurochemical Research, 37, 875-884.

http://dx.doi.org/10.1007/s11064-011-0682-0

[49] Dixit, A., Srivastava, G., Verma, D., Mishra, M., Singh, P.K., Prakash, O. and Singh, M.P. (2013) Minocycline, levodopa and MnTMPyP induced chamges in the mitochondrial protein profile of MPTP and maneb and paraquat mice models of Parkinson's disease. Biochimica et Biophysica Acta, 1832, 1227-1240.

[50] Somayajulu-Nit, M., Sandhu, J.K., Cohen, J., Sikorska, M., Sridhar, T.S., Matei, A., Borowy-Borowski, H., and Pandey, S. (2009) Paraquatinduces oxidative stress, neuronal loss in substantianigra region and parkinsonism in adult rats: Neuroprotection and amelioration of symptoms by water soluble formulation of coenzyme Q10. BMC Neuroscience, 10, 1-12.

[51] Ahmad, M., Saleem, S., Ahmad, A.S., Ansari, M.A., Yousuf, S., Hoda, M.N. and Islam, F. (2005) Neuroprotective effects of Withaniasomnifera on 6-hydroxydopamine induced Parkinsonism in rats. Human \& Experimental Toxicology, 24, 137-147. http://dx.doi.org/10.1191/0960327105ht509oa

[52] Dhanasekaran, M., Tharakan, B., and Manyam, B.V. (2008) Antiparkinson drug-Mucuna pruriens shows antioxidant and metal chelating activity. Phytotherapy Research, 22, 6-11. http://dx.doi.org/10.1002/ptr.2109

[53] Whishaw, I.Q., Li, K., Whishaw, P.A., Gorny, B. and Metz, G.A. (2008) Use of rotorod as a method for the qualitative analysis of walking in rat. Journal of Visualized Experiments, 22, 1030. 